\title{
Association between preoperative potential sarcopenia and survival of cancer patients undergoing major surgical procedures
}

\section{Associação entre provável sarcopenia pré-operatória e sobrevida de pacientes oncológicos submetidos a operações de grande porte}

Thayse Emanuell Godoy Behne ${ }^{1}$; ; Diana Borges Dock-Nasimento ${ }^{1,2}$; Jessika Cadavid Sierra ${ }^{1}$; Hadassa Hillary Novaes Pereira Rodrigues²; Maristela luft Palauro²; Francilene Oliveira Andreo'; Mariana Borges Silva-Thez3; José Eduardo de-Aguilar-Nascimento, TCBC-MG ${ }^{1,4}$.

\section{A B S T R A C T}

\begin{abstract}
Objective: to evaluate the impact of probable sarcopenia (PS) on the survival of oncological patients submitted to major surgeries. Method: prospective cohort bicentrical study enrolling adult oncological patients submitted to major surgeries at Cancer Hospital and Santa Casa de Misericordia in Cuiabá-MT. The main endpoint was the verification of postoperative death. Demographic and clinical data was collected. PS was defined as the presence of 1) sarcopenia risk assessed by SARC-F questionnaire and 2) low muscle strength measured by dynamometry. The cumulative mortality rate was calculated for patients with either PS or non PS using Kaplan Meier curve. The univariate and multivariate Cox regression model was used to evaluate the association of mortality with various investigated confounding variables. Results: a total of 220 patients with a mean (SD) age of $58.7 \pm 14.0$ years old, $60.5 \%$ males participated of the study. Patients with PS had higher risk to postoperative death ( $R R=5.3595 \% \mathrm{Cl} 1.95-14.66 ; \mathrm{p}=0,001)$ and for infectious complications ( $R R=2.4595 \% \mathrm{Cl} 1.12-5.33 ; p=0.036)$. The 60 days mean survival was shorter for patients with PS: 44 (IQR=32-37) vs 58 (IQR=56-59) days (log rank <0,001). The Cox multivariate regression showed that PS was an independent risk factor $(\mathrm{HR}=5.8$ 95\% Cl 1.49-22.58; $p=0.011$ ) for mortality. Conclusion: patients bearing PS submitted to major oncological surgery have less probability of short term survival and preoperative PS is an independent risk for postoperative mortality.
\end{abstract}

Keywords: Surgical Oncology. Sarcopenia. Mortality. Postoperative Complications.

\section{INTRODUCTION}

In the last decades, there has been a significant increase in the incidence of cancer accompanied by a high mortality rate ${ }^{1}$. In this scenario, the operation is one of the mainstays of the treatment available for patients with cancer $^{2}$. It is estimated for 2030 that of the 21.6 million cancer patients, 17.3 million will require surgery ${ }^{2}$.

However, despite the advances in surgical procedures and in the perioperative management techniques, some factors are predictive of complications and can increase postoperative mortality. In this sense, malnutrition and, more recently, the presence of sarcopenia, in cancer patients may increase the risk of postoperative complications and death. Thus, the success of surgery and of postoperative evolution also depends on this important risk factor ${ }^{3-5}$.

The body composition plays an important role in the evolution of oncological diseases, as well as in response to treatment and quality of life of patients. In the last decade, the sarcopenia syndrome, characterized by the generalized and progressive loss of skeletal muscle

1 - Universidade Federal de Mato Grosso, Programa de Pós-graduação em Ciências da Saúde, Faculdade de Ciências Médicas - Cuiabá - MT - Brasil 2 - Universidade Federal de Mato Grosso, Faculdade de Nutrição - Cuiabá - MT - Brasil 3 - Centro Universitário UNIVAG, Faculdade de Nutrição - Várzea Grande - MT - Brasil 4 - Centro Universitário UNIVAG, Diretoria curso de Medicina - Várzea Grande - MT - Brasil 
and its function, has been associated with increased likelihood of adverse outcomes, including falls, fractures, disability and mortality, raising great concern among elderly and cancer patients ${ }^{6-9}$. This is because the presence of this syndrome is also associated with the increase of hospital admissions, longer hospitalization, increase of postoperative complications and readmissions ${ }^{10-13}$.

The etiology of sarcopenia is multifactorial. It is classified as primary or age-related when no other specific cause is evidenced, and secondary, when causal factors other than aging are evident, such as the presence of systemic disease, physical inactivity and inadequate energy or protein intake ${ }^{7}$. Many studies have shown that sarcopenia as a negative prognostic factor in several clinical aspects of the cancer patient, such as treatment tolerance and overall survival ${ }^{14-16}$.

However, in surgical oncology, sarcopenia received less attention, and evaluation of the muscle mass and / or function is not part of the routine preoperative approach in many care centers for patients with cancer ${ }^{4}$. Thus, the assessment of probable sarcopenia (PS) or preoperative sarcopenia in patients with cancer is necessary to evaluate the outcomes along the postoperative period.

Therefore, considering its clinical relevance, the European Working Group on Older People in Sarcopenia (EWGSOP2) ${ }^{7}$, published in 2019, recommends using the SARC F questionnaire (Strength, Assistance with walking, Rise from the chair, Climbing stairs, and Falls) to screen for sarcopenia. This questionnaire is useful, simple, inexpensive, and easily applicable for screening and further contribution to the diagnosis of sarcopenia 17,18. An ally of the SARC-F, and indicated by it, is the measuring of muscle strength for the diagnosis of SP7. The muscle strength changes rapidly and precedes the anthropometric changes, which allows more sensitive and rapid detection of sarcopenia ${ }^{17-20}$.

Thus, considering that few national studies have evaluated the impact of sarcopenia in cancer patients who are candidates for surgical procedures, this research aimed to evaluate the impact of preoperative PS in the survival of cancer patients undergoing major operations.

\section{Methods}

This was a bicentric, prospective, cohort study conducted from July 2018 to April 2019, with adult cancer patients (age $\geq 18$ years) admitted to the Cuiabá Cancer Hospital and to the Santa Casa de Misericordia. The study was approved by the Ethics in Research Committee of the Federal University of Mato Grosso (UFMT), under number 2,666,168 (CAAE 89216318.8.0000.8124). Patients who agreed to participate in the study signed an informed consent form (ICF).

\section{Inclusion and exclusion criteria}

We included adults with cancer and candidates for major oncological operations, which we defined as the ones with high probability of loss of fluids and blood, according to opinion 006/2015 of the Federal Council of Medicine $^{21}$. We excluded patients diagnosed with nonmelanoma skin cancer, advanced disease, and those who refused to sign the ICF or declined to participate in the study at any stage. We also excluded previously included patients whose data were lost or who have had operations suspended for any reason, or, even who were transferred to another hospital in the postoperative period.

\section{Investigated variables and data collection}

We classified patients as having PS or not preoperatively as defined below. The main outcome variable was death. As covariates, we recorded the presence of PS in the preoperative period, demographic data, body weight $(\mathrm{kg})$, body mass index $(\mathrm{kg} / \mathrm{m} 2)$, nutritional status, American Society of Anesthesiologists (ASA) score, type of major surgery according to the location of the tumor, operative time (minutes) and hospital stay (in days, until discharge or death), and postoperative infectious complications. We collected the data in the preoperative period, about one to two hours before surgery and in the postoperative period, until hospital discharge or death. We recorded the survival time up to 60 days after admission.

\section{Nutritional status}

We determined the nutritional status of the studied patients according to the subjective global assessment (SGA). Nourished patients were classified as 
SGA-A, potentially or moderately malnourished, as SGA-B, and severe malnourished, as SGA-C ${ }^{22}$.

\section{Diagnosis of probable sarcopenia}

We defined probable sarcopenia (PS) when the patient who presents, in the immediate preoperative period, risk of sarcopenia by the SARC-F questionnaire and low muscle strength (Kgf). The SARC-F questionnaire consists of five questions that evaluate strength, walking, getting up from a chair, climbing stairs and a history of falls. The ratings vary from 0 to 10 points, with $0-2$ points for each item. We considered patients who achieved a SARC $F \geq 4$ as in risk of sarcopenia ${ }^{17,18}$. We assessed muscle strength by the handgrip strength (HGS; Kgf), measured in the dominant hand with the aid of a hydraulic dynamometer (Saehan Corporation, Masan, Corea ${ }^{11}{ }^{19}$. We classified patients as having low muscle strength according to the cutoffs of $<27 \mathrm{Kgf}$ and $<16 \mathrm{Kgf}$, for men and women, respectively?

\section{Postoperative infectious complications}

We considered infectious complications the presence of pneumonia, infection at the surgical site, dehiscence of anastomosis or abdominal wall, urinary tract infection, and sepsis. All definitions of infectious complications were cited in other articles published by the same group ${ }^{23,24}$. We also classified complications by the Clavien-Dindo criteria ${ }^{25}$.

\section{Statistical analysis}

We used the Kolmogorov-Smirnov test to determine the normality of continuous data. We presented the normally distributed data in means and standard deviations, and those distributed in a non-normal way, in median and interquartile range (IQR). We used the Chisquare test (relative risk and $95 \%$ confidence interval) to determine the association of PS with death and infectious complications. We computed the Odds Ratio and its 95\% confidence interval $(\mathrm{OR}, 95 \% \mathrm{Cl})$ to determine the association of PS with the demographic variables.

We used the Kaplan-Meier non-parametric test to estimate the probability of survival (days) of patients with and without PS, compared by the Log-Rank test. We defined the survival time (median, interquartile rage) as the time in days from surgery until death or censoring (discharged cases).

Then, we used the univariate and multivariate Cox Proportional Hazards Regression, having the hazard ratio (HR) as an effect measure, with respective 95\% confidence intervals to evaluate the association of mortality with categorical and continuous variables (clinical and demographic data). To avoid data collinearity in relation to nutritional status, in the univariate Cox regression we used only the severely malnourished classification (SGA-C).

In the multivariate Cox Proportional Hazards Regression, we included variables related to the occurrence of the event "survival" in the univariate analysis, with $p$ value $<0.20$. The variables selected for fitting the multivariate model were probable sarcopenia (PS), infectious complications, and digestive tract surgery.

We set the statistical significance threshold at $5 \%(p<0.05)$. We used the Statistical Package for the Social Sciences 20.0 (SPSS Statistics; IBM, Armonk, NY, USA) for statistical analysis.

\section{RESULTS}

\section{Sample and patients characterization}

From 338 eligible patients, we excluded 12 due to non melanoma skin cancer, 14 due to advanced disease, 13 due to data loss, and 79 due to suspension of the procedure. Hence, 220 patients undergoing major operations participated in the study. They had average age of $58.7 \pm 14.0$ years, $111(50.5 \%)$ being elderly. Table 1 brings the other clinical and demographic data.

\section{Diagnosis of probable sarcopenia}

Preoperatively, 39 (17.7\%) patients were at risk for sarcopenia according to the SARC-F. The mean HGS was $31.2 \pm 11.5 \mathrm{Kgf}$, with $27(12.3 \%)$ patients having low HGS. Fourteen patients (6.4\%) had PS. Among the elderly, PS was present in $6.3 \%(7 / 111)$. 
Table 1. Clinical and demographic characteristics of the studied patients.

\begin{tabular}{|c|c|}
\hline Variables & Values \\
\hline Age (years) $(A \pm S D)$ & $58.0 \pm 14.0$ \\
\hline Elderly (n;\%) & $111(50.5)$ \\
\hline \multicolumn{2}{|l|}{ Gender (n;\%) } \\
\hline Female & $109(49.5)$ \\
\hline Male & $111(50.5)$ \\
\hline Body weight $(\mathrm{Kg})(\mathrm{A} \pm \mathrm{SD})$ & $71.6 \pm 15.8$ \\
\hline BMI (kg/m2) (M; IQR) & $26,1(23.0-30.1)$ \\
\hline \multicolumn{2}{|l|}{ Nutritional status (n;\%) } \\
\hline SGA-A & $120(54.5)$ \\
\hline SGA-B & $71(32.3)$ \\
\hline SGA-C & $29(13.2)$ \\
\hline ASA score I and II (n;\%) & $202(91.8)$ \\
\hline \multicolumn{2}{|l|}{$\begin{array}{l}\text { Type of operation according } \\
\text { to tumor location }\end{array}$} \\
\hline Urological & $86(39.1)$ \\
\hline Digestive tract & $69(31.4)$ \\
\hline Breast & $29(13.2)$ \\
\hline Head and neck & $17(7.7)$ \\
\hline Others & $19(8.6$ \\
\hline $\begin{array}{l}\text { Surgery time (minutes) } \\
(\mathrm{M} ; \mathrm{IQR})\end{array}$ & $125(90-205)$ \\
\hline $\begin{array}{l}\text { Length of hospital stay (days) } \\
\text { (M; IQR) }\end{array}$ & $3(2-7)$ \\
\hline $\begin{array}{l}\text { Infectious complications } \\
(n ; \%)\end{array}$ & 35 (15.9) \\
\hline Death $(n ; \%)$ & $15(6.8)$ \\
\hline
\end{tabular}

BMI: body mass index; SGA: subjective global assessment; ASA: American Society of Anesthesiologists.

According to data distribution, values are expressed as average and standard deviation $(A \pm S D)$, number and percentage $(n ; \%)$, and median and interquartile range $(M ; I Q R)$.

In the preoperative period, patients undergoing digestive tract operations were those who were more likely to have PS (OR = 3.16, 95\% Cl 1.05 9.5, $p=0.032)$. The data also showed that patients diagnosed with preoperative severe malnutrition were about three times more likely to have PS $(\mathrm{OR}=3.06,95 \% \mathrm{Cl} 1.386 .80 ; \mathrm{p}$ $=0.010$ ). There was no association between PS and the other variables studied (ASA 1 and 2, elderly, sex and urological surgery).

\section{Postoperative complications}

In the postoperative period, $37.7 \%(n=83)$ of patients experienced at least one complication, of which $15.9 \%$ ( $n=35$ ) were infection. In addition, in most of the cases that had any complications, they were mild, 61 (27.7\%) being classified as Clavien-Dindo I or II.

\section{Survival}

The occurrence of death was significantly higher among patients with PS [28.6\% (4/14) vs 5.3\% $(11 / 206) ; p=0.001]$. The total survival time in 58 days was 57 (55-58) days. The Kaplan-Meier curve showed that the survival average during the study period of 60 days was shorter for patients with PS, 44 (IQR = 32 37) vs. 58 (IQR = 56 59) days (Log Rank < 0.001), as shown in Figure 1.

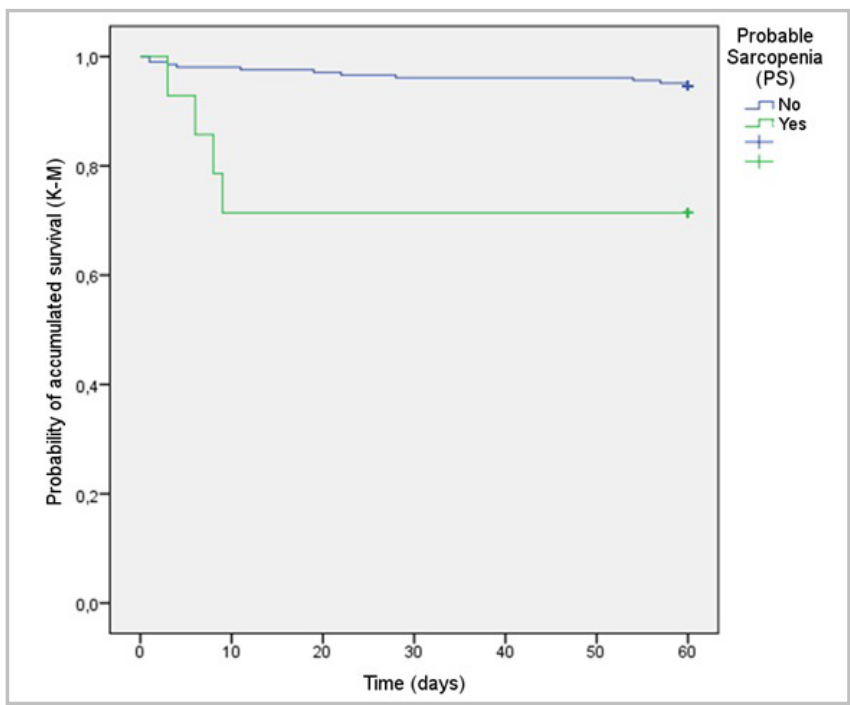

Figure 1. Probability of accumulated survival over the 60-day period in patients with and without probable sarcopenia (PS).

\section{Univariate Cox Regression for mortality associated with clinical and demographic characteristics.}

The univariate Cox regression analysis showed that PS ( $H R=9.96, p=0.001)$, infectious complications $(H R=4.8, p=0.031)$, and patients undergoing digestive tract operations $(H R=5.55, p=0.028)$ presented an increased risk for the occurrence of death (Table 2). 
Table 2. Univariate Cox Regression Analysis for the association of mortality with clinical and demographic characteristics of the studied patients.

\begin{tabular}{lccc}
\hline Event & $\begin{array}{c}\text { Hazard } \\
\text { Ratio }\end{array}$ & $95 \% \mathrm{Cl}$ & $\mathrm{p}$ \\
\hline $\begin{array}{l}\text { Probable } \\
\text { sarcopenia } \\
\text { Infectious }\end{array}$ & 9.96 & $2.66-37.37$ & 0.001 \\
$\begin{array}{l}\text { complications } \\
\text { Digestive tract }\end{array}$ & 4.80 & $1.16-19.9$ & 0.031 \\
$\begin{array}{l}\text { surgery } \\
\text { ASA I and II }\end{array}$ & 5.55 & $1.20-25.7$ & 0.028 \\
$\begin{array}{l}\text { Surgery time } \\
\text { (min) }\end{array}$ & 0.90 & $0.11-7.14$ & 0.922 \\
$\begin{array}{l}\text { Age (years) } \\
\text { Elderly }\end{array}$ & 1.00 & $0.99-1.00$ & 0.914 \\
$\begin{array}{l}\text { Sex } \\
\text { Body Weight } \\
\text { (Kg) }\end{array}$ & 0.82 & $0.28-2.40$ & 0.722 \\
$\begin{array}{l}\text { BMI (kg/m2) } \\
\text { SGA-C }\end{array}$ & 0.92 & $0.26-3.22$ & 0.896 \\
\hline
\end{tabular}

95\% Cl: 95\% confidence interval; ASA: American Society of Anesthesiologists, BMI: body mass index, SGA: Subjective global assessment.

\section{Multivariate Cox Regression for mortality associated with clinical features}

As shown in Table 3, in the multivariate Cox regression adjusted for PS, surgery of the digestive tract, and presence of infectious complications, only the effect of PS remained as risk of death, ie, PS was an independent risk factor $(H R=5.8,95 \% \mathrm{Cl} 1.4922 .58, \mathrm{p}=0.011)$ for the mortality of cancer patients undergoing major operations.

Table 3. Multivariate Cox Regression Analysis for the association of death with the characteristics of the studied patients.

\begin{tabular}{lccc}
\hline Condition & $\begin{array}{c}\text { Hazard } \\
\text { Ratio }\end{array}$ & $95 \% \mathrm{Cl}$ & $\mathrm{p}$ \\
\hline $\begin{array}{l}\text { Probable } \\
\text { sarcopenia }\end{array}$ & 5.80 & $1.49-22.58$ & 0.011 \\
$\begin{array}{l}\text { Digestive } \\
\text { tract surgery }\end{array}$ & 3.73 & $0.77-18.07$ & 0.102 \\
$\begin{array}{l}\text { Infectious } \\
\text { complications }\end{array}$ & 2.57 & $0.62-10.74$ & 0194 \\
\hline
\end{tabular}

IC 95\%: confidence interval of 95\%.

\section{DISCUSSION}

The results showed that cancer patients with PS undergoing major operation presented a lower probability of survival in 60 days. In addition, the diagnosis of PS was an independent risk factor for mortality. The data revealed that the risk of sarcopenia and low muscle strength are associated with a worse postoperative outcome, corroborating the results of other authors ${ }^{26-29}$.

A study with 6,447 patients submitted to abdominal cancer surgery showed an association of sarcopenia with a higher occurrence of readmissions and postoperative complications ${ }^{27}$. In addition, sarcopenia was a risk factor for reduction of survival, in agreement with our results. Previously, another study from our group had found that patients undergoing major digestive tract operations and decreased HGS had 50\% more risk of complications and five times more risk of death when compared with normal HGS individuals ${ }^{26}$.

Other studies have shown that the reduction in functional capacity, as determined by strength, is a strong predictor of mortality in patients with different clinical conditions ${ }^{30-33}$. Moreover, muscle strength, according to the latest European Consensus ${ }^{7}$ and other studies $^{34,35}$, gained more importance to the diagnosis of probable sarcopenia and sarcopenia compared with the determination of muscle mass ${ }^{36,37}$. Our data showed that $12.3 \%$ of the patients had low HGS in the preoperative period.

Furthermore, according to our results, patients with PS presented twice more risk for postoperative infectious complications. Recent studies found similar results $^{9,11,32,38,39}$, thus reinforcing the importance of early diagnosis of sarcopenia or PS. Supporting these data, a meta-analysis published by Wang et al. in 202030 showed that the presence of sarcopenia in cancer patients undergoing esophagectomy increased the chance of pneumonia and anastomosis dehiscence in the postoperative period.

We also found that patients submitted to digestive tract operations, different from the urological ones, were those who presented more than three times the chance of being with PS before undergoing the surgical intervention. This reaffirms the association that exists between the presence of cancer of the digestive 
tract, especially in the upper part and in the head and neck, with alterations related to the intake of nutrients and nutritional condition 3,4,26,40.

Patients classified as having severe malnutrition by the SGA were three times more likely to have PS in the preoperative period. This does not surprise us, since malnourished patients usually have quite low muscle mass. This functional change was recently established by to the Global Leadership Initiative on Malnutrition (GLIM) as a criterion for classification of malnutrition ${ }^{7,41}$. Malnourished patients often also display changes in body composition $7,42,43$.

Our data showed, with significant relevance, that patients with PS were less likely to survive in 60 days than those without PS. Many cancers, particularly of the digestive tract, which were the second leading cause of operations of our sample, occur with lower lifespan 1,28,32. For instance, gastric cancer, whose treatment is predominantly surgical, is the fifth most common cancer and the third leading cause of death by cancer worldwide". Huang et al. (2020)29 showed that the overall and diseasefree survival were lower among the sarcopenic patients receiving neoadjuvant treatment for esophageal cancer. Moreover, sarcopenic patients sustained more adverse events, such as mucositis, neutropenic fever, and lower muscle mass index than the non-sarcopenic individuals did.

Li et al. ${ }^{44}$, in a recent meta-analysis comprising 2,264 patients diagnosed with urological cancer, showed that the ones who were sarcopenic in the preoperative period had shorter survival. The authors also stated that sarcopenia could serve as a promising prognostic marker for patients with urological cancer.

Therefore, the identification of PS is of great importance for the initiation of treatment strategies before the operation ${ }^{5,45}$. This may reduce the occurrence of complications and death. For though there is great advancement in nutritional therapy, in surgical techniques and in fast track type, multimodal programs of postoperative recovery acceleration ${ }^{46-48}$, the cancer patients, the malnourished, and the sarcopenic ones still present with increased risk of morbidity and mortality $12,13,29,32,49$.

We must also add that despite the PS's scientific and clinical relevance, this muscle syndrome is rarely diagnosed and treated in clinical practice ${ }^{50}$. In contrast, the latest European Consensus states that in face of the risk of sarcopenia assessed by SARC-F, one must start preventive nutritional intervention. This indication of the Consensus values the power of preoperative screening. It is important to note that both the SARC $F$ and the HGS assessments, in addition to being simple, rapid and low cost, can be performed at bedside with the patient lying down or sitting, which optimizes time.

Thus, a research group recently created in Brazil a protocol called SARCPRO (Protocol Proposal for Sarcopenia in Hospitalized Patients) ${ }^{51}$. The protocol suggests nutritional intervention with protein supplementation associated with motor rehabilitation, highlighting the importance of a multi-professional team in this context.

In this sense, a study of patients submitted to radical cystectomy after consuming oral nutritional supplement twice a day for eight weeks in the perioperative period showed that these patients had a lower prevalence of sarcopenia, complications and hospital readmissions $\mathrm{s}^{52}$.

The results of our study, however, must be carefully evaluated because the sample is small and we evaluated patients undergoing different major operations. The study has limitations, such as the use of a hydraulic dynamometer of a brand different from the Jamar®, the one validated to obtain the cutoff point mentioned in the method and indicated by the European Consensus ${ }^{7}$. Another point that can be considered as a limitation was not excluding patients who already had cachexia. Nevertheless, we can consider that only patients who were candidates for operations participated in the study, with therapeutic, not just palliative, possibilities.

On the other hand, we prospectively evaluated all patients, and they underwent major cancer operations. Thus, the data from this study allow us to conclude that patients with PS undergoing major oncological procedures have lower probability of short-term survival. Moreover, preoperative PS is an independent risk factor for postoperative mortality.

\section{ACKNOWLEDGMENTS}

This work was carried out with the support of the Brazilian Coordination for the Improvement of Higher Education Personnel - CAPES, Financing Code 001. 


\title{
R E S U M O
}

\begin{abstract}
Objetivo: avaliar o impacto de provável sarcopenia (PS) pré-operatória na sobrevida de pacientes oncológicos submetidos a operações de grande porte. Métodos: estudo bicêntrico de coorte prospectivo, realizado com pacientes oncológicos adultos, submetidos a operação de grande porte no Hospital de Câncer e na Santa Casa de Misericórdia em Cuiabá-MT. A variável principal foi a ocorrência de óbito pós-operatório. Coletou-se dados demográficos, clínicos e o diagnóstico de PS, definido pela presença de: 1) risco de sarcopenia pelo questionário SARC-F e 2) baixa força muscular (Kgf) mensurada pela dinamometria. Calculou-se a taxa de sobrevida acumulada para os pacientes com e sem PS pela curva de Kaplan-Meier. Aplicou-se o modelo de regressão de Cox uni e multivariado para avaliar a associação da mortalidade com covariáveis de confundimento investigadas. Resultados: participaram do estudo 220 pacientes com idade média (DP) de 58,7 $\pm 14,0$ anos, sendo 60,5\% do sexo masculino. Quatorze $(6,4 \%)$ pacientes foram considerados com PS. Os pacientes com PS apresentaram risco aumentado para a ocorrência de óbito (RR=5,35 IC95\% 1,95-14,66; $p=0,001)$ e para complicações infecciosas ( $R R=2,45$ IC95\% 1,12-5,33; $p=0,036$ ). A sobrevida média em 60 dias, foi menor para os pacientes com PS: 44 (IIQ=32-37) vs 58 (IIQ=56-59) dias (log rank<0,001). A regressão Multivariada de Cox, mostrou que a PS foi fator de risco independente (HR=5, 8 IC95\% 1,49-22,58; $p=0,011)$ para a mortalidade. Conclusão: os pacientes com PS submetidos a operações oncológicas de grande porte apresentam menor probabilidade de sobrevida a curto prazo e a PS pré-operatória, é fator de risco independente para mortalidade pós-operatória.
\end{abstract}

Palavras chave: Oncologia Cirúrgica. Sarcopenia. Mortalidade. Complicações Pós-Operatórias.

\section{REFERENCES}

1. Bray F, Ferlay J, Soerjomataram I, Siegel RL, Torre LA, Jemal A. Global cancer statistics 2018: GLOBOCAN estimates of incidence and mortality worldwide for 36 cancers in 185 countries. CA Cancer J Clin. 2018;68(6):394-424.

2. Sullivan R, Alatise OI, Anderson BO, Audisio R, Autier P, Aggarwal A, et al. Global cancer surgery: delivering safe, affordable, and timely cancer surgery. Lancet Oncol. 2015;16(11):1193-224.

3. Arends J, Baracos V, Bertz H, Bozzetti F, Calder PC, Deutz NEP, et al. ESPEN expert group recommendations for action against cancer-related malnutrition. Clin Nutr. 2017;36(5):1187-96.

4. Simonsen $C$, de Heer $P$, Bjerre ED, Suetta C, Hojman $P$, Pedersen BK, et al. Sarcopenia and postoperative complication risk in gastrointestinal surgical oncology: a meta-analysis. Ann Surg. 2018;268(1):58-69.

5. Prado CM, Purcell SA, Laviano A. Nutrition interventions to treat low muscle mass in cancer. J Cachexia Sarcopenia Muscle. 2020;11(2):366-80.

6. Fearon K, Strasser F, Anker SD, Bosaeus I, Bruera E, Fainsinger $\mathrm{RL}$, et al. Definition and classification of cancer cachexia: an international consensus. Lancet Oncol. 2011;12(5):489-95.

7. Cruz-Jentoft A, Bahat G, Bauer JM, Boirie Y, Bruyere OTC, Cederholm T, et al. Sarcopenia: revised European consensus on definition and diagnosis.
Age Ageing. 2019; 48:16-31.

8. Colloca G, Di Capua B, Bellieni A, Cesari M, Marzetti E, Valentini $V$, et al. Muscoloskeletal aging, sarcopenia and cancer. J Geriatr Oncol. 2019;10(3):504-09.

9. Lieffers JR, Bathe OF, Fassbender K, Winget M, Baracos VE. Sarcopenia is associated with postoperative infection and delayed recovery from colorectal câncer resection surgery. Br J Cancer. 2012;107(6):931-6.

10. Bauer J, Morley JE, Schols AMWJ, Ferrucci L, Cruz-Jentoft AJ, Dent E, et al. Sarcopenia: A time for action. An SCWD Position Paper. J Cachexia Sarcopenia Muscle. 2019;10(5):956-61.

11. Peterson SJ, Braunschweig CA. Prevalence of sarcopenia and associated outcomes in the clinical setting. Nutr Clin Pract. 2016;31(1):40-8.

12. Zhou CJ, Zhang FM, Zhang FY, Yu Z, Chen XL, Shen $X$, et al. Sarcopenia: a new predictor of postoperative complications for elderly gastric cancer patients who underwent radical gastrectomy. J Surg Res. 2017;211:137-46.

13. Hopkins JJ, Reif RL, Bigam DL, Baracos VE, Eurich DT, Sawyer MB. The impact of muscle and adipose tissue on long-term survival in patients with stage I to III colorectal cancer. Dis Colon Rectum. 2019;62(5):549-60.

14. Yip C, Goh V, Davies A, Gossage J, Mitchell-Hay $\mathrm{R}$, Hynes $\mathrm{O}$, et al. Assessment of sarcopenia and changes in body composition after neoadjuvant 
chemotherapy and associations with clinical outcomes in oesophageal cancer. Eur Radiol. 2014;24(5):998-1005.

15. Prado CM, Lieffers JR, McCargar LJ, Reiman T, Sawyer MB, Martin L, et al. Prevalence and clinical implications of sarcopenic obesity in patients with solid tumours of the respiratory and gastrointestinal tracts: A population-based study. Lancet Oncol. 2008;9(7):629-35.

16. Prado CM, Baracos VE, McCargar LJ, Reiman T, Mourtzakis $M$, Tonkin $K$, et al. Sarcopenia as a determinant of chemotherapy toxicity and time to tumor progression in metastatic breast cancer patients receiving capecitabine treatment. Clin Cancer Res. 2009;15(8):2920-26.

17. Malmstrom TK, Morley JE. SARC-F: a simple questionnaire to rapidly diagnose sarcopenia. J Am Med Dir Assoc. 2013;14(8):531-2.

18. Malmstrom TK, Miller DK, Simonsick EM, Ferrucci L, Morley JE. SARC-F: a symptom score to predict persons with sarcopenia at risk for poor functional outcomes. J Cachexia Sarcopenia Muscle. 2016;7(1):28-36.

19. Correa-Arruda WS, Vaez IDA, Aguilar-Nascimento $J E$, Dock-Nascimento DB. Effects of overnight fasting on handgrip strength in inpatients. Einstein (Sao Paulo). 2019;17(1):eAO4418.

20. Humphreys J, de la Maza P, Hirsch S, Barrera G, Gattas $V$, Bunout D. Muscle strength as a predictor of loss of functional status in hospitalized patients. Nutrition. 2002;18(7-8):616-20.

21. Conselho Federal de Medicina. Parecer número 006/2015. Disponível em: http:// www.portalmedico.org.br/pareceres/crmes/ pareceres/2015/0006_2015.pdf

22. Detsky AS, McLaughlin JR, Baker JP, Johnston N, Whittaker $S$, Mendelson RA. What is subjective global assessment of nutritional status? JPEN J Parenter Enteral Nutr. 1987;11(1):8-13.

23. Aguilar-Nascimento JE, Marra JG, Slhessarenko N, Fontes CJ. Efficacy of National Nosocomial Infection Surveillance score, acute-phase proteins, and interleukin- 6 for predicting postoperative infections following major gastrointestinal surgery. Sao Paulo Med J. 2007;125(1):34-41
24. Bicudo-Salomão $A$, Salomão RF, Cuerva $M P$, Martins MS, Dock-Nascimento DB, AguilarNascimento JE. Factors related to the reduction of the risk of complications in colorectal surgery within perioperative care recommended by the ACERTO protocol. Arq Bras Cir Dig. 2019;32:e1477.

25. Moreira LF, Pessôa MC, Mattana DS, Schmitz FF, Volkweis BS, Antoniazzi JL, et al. Adaptação cultural e teste da escala de complicações cirúrgicas de Clavien-Dindo traduzida para o Português do Brasil. Rev Col Bras Cir. 2016;43(3):141-8.

26. Bragagnolo R, Caporossi FS, Dock-Nascimento DB, Aguilar-Nascimento JE. Handgrip strength and adductor pollicis muscle thickness as predictors of postoperative complications after major operations of the gastrointestinal tract. e-SPEN. 2011;6:21-6.

27. Valente $\mathrm{KP}$, Almeida $\mathrm{BL}$, Lazzarini TR, Souza VF, Ribeiro TSC, Guedes de Moraes RA, et al. Association of Adductor Pollicis Muscle Thickness and Handgrip Strength with nutritional status in cancer patients. PLoS One. 2019;14(8):e0220334.

28. Zhang S, Tan S, Jiang Y, Xi Q, Meng Q, Zhuang Q, et al. Sarcopenia as a predictor of poor surgical and oncologic outcomes after abdominal surgery for digestive tract cancer: A prospective cohort study. Clin Nutr. 2019;38(6):2881-88.

29. Huang $\mathrm{CH}$, Lue $\mathrm{KH}$, Hsieh TC, Liu SH, Wang TF, Peng TC. Association between sarcopenia and clinical outcomes in patients with esophageal cancer under neoadjuvant therapy. Anticancer Res. 2020;40(2):1175-81.

30. Wang PY, Xu LD, Chen XK, Xu L, Yu YK, Zhang RX, et al. Sarcopenia and Short-Term Outcomes After Esophagectomy: A Meta-analysis. Ann Surg Oncol. Epub 2020 Feb 10.

31. Springer J, Springer JI, Anker SD. Muscle wasting and sarcopenia in heart failure and beyond: update 2017. ESC Heart Fail. 2017;4(4):492-98.

32. Okamura H, Kimura N, Mieno M, Yuri K, Yamaguchi A. Preoperative sarcopenia is associated with late mortality after off-pump coronary artery bypass grafting. Eur J Cardiothorac Surg. 2020;58(1):1219.

33. Yang $Z$, Zhou $X, M a ~ B$, Xing $Y$, Jiang $X$, Wang $Z$. Predictive value of preoperative sarcopenia 
in patients with gastric cancer: A meta-analysis and systematic review. J Gastrointest Surg. 2018; 22(11):1890-902.

34. Lin J, Zhang W, Chen W, Huang $Y$, Wu R, Chen $X$, et al. Muscle mass, density, and strength are necessary to diagnose sarcopenia in patients with gastric cancer. J Surg Res. 2019;241:141-48.

35. Choi JY, Kim Kl, Choi Y, Ahn SH, Kang E, Oh HK, et al. Comparison of multidimensional frailty score, grip strength, and gait speed in older surgical patients. J Cachexia Sarcopenia Muscle. 2020;11(2):432-40.

36. Sato T, Aoyama T, Hayashi T, Segami K, Kawabe $T$, Fujikawa $H$, et al. Impact of preoperative hand grip strength on morbidity following gastric cancer surgery. Gastric Cancer. 2016;19(3):1008-15.

37. Norman K, Stobäus N, Gonzalez MC, Schulzke J, Pirlich M. Hand grip strength: Outcome predictor and marker of nutritional status. Clin Nutr. 2011;30(2):135-42.

38. Wang $S L$, Zhuang $C L$, Huang $D D$, Pang $W Y$, Lou N, Chen FF, et al. Sarcopenia adversely impacts postoperative clinical outcomes following gastrectomy in patients with gastric cancer: A prospective study. Ann Surg Oncol. 2016;23(2):55664.

39. Tamura T, Sakurai K, Nambara M, Miki Y, Toyokawa $T$, Kubo $N$, et al. Adverse effects of preoperative sarcopenia on postoperative complications of patients with gastric cancer. Anticancer Res. 2019;39(2):987-92.

40. Ackerman D, Laszlo M, Provisor A, Yu A. Nutrition Management for the Head and Neck Cancer Patient. Cancer Treat Res. 2018;174:187-208.

41. Cederholm T, Jensen GL, Correia MITD, Gonzalez MC, Fukushima R, Higashiguchi T, et al. GLIM Core Leadership Committee; GLIM Working Group. GLIM criteria for the diagnosis of malnutrition - A consensus report from the global clinical nutrition community. Clin Nutr. 2019;38(1):1-9.

42. Cederholm T, Barazzoni R, Austin P, Ballmer P, Biolo $G$, Bischoff SC, et al. ESPEN guidelines on definitions and terminology of clinical nutrition. Clin Nutr. 2018;36:49-64.

43. Zhang $X L$, Zhang Z, Zhu YX, Tao J, Zhang $Y$, Wang $Y Y$, et al. Comparison of the efficacy of Nutritional
Risk Screening 2002 and Mini Nutritional Assessment Short Form in recognizing sarcopenia and predicting its mortality. Eur J Clin Nutr. 2020;74(7):1029-37.

44. Li J, Deng $Y$, Zhang $M$, Cheng $Y$, Zhao $X$, Ji Z. Prognostic value of radiologically determined sarcopenia prior to treatment in urologic tumors: A meta-analysis. Medicine (Baltimore). 2019;98(38):e17213.

45. Horie LM, Barrére APN, Castro MG, Liviera AMB, Carvalho $A M B$, Pereira $A$, et al. Diretriz BRASPEN de terapia nutricional no paciente com câncer. BRASPEN J. 2019;34 (Supl 1):2-32.

46. Aguilar-Nascimento JE, Salomão $A B$, Waitzberg $D L$, Dock-Nascimento DB, Correa MITD, Campos ACL, et al. Diretriz ACERTO de intervenções nutricionais no perioperatório em cirurgia geral eletiva. Rev Col Bras Cir. 2017;44(6): 633-48.

47. Brindle $M$, Nelson G, Lobo DN, Ljungqvist $O$, Gustafsson UO. Recommendations from the ERAS ${ }^{\circledR}$ Society for standards for the development of enhanced recovery after surgery guidelines. BJS Open. 2020;4(1):157-63.

48. Weimann A, Braga M, Carli F, Higashiguchi $T$, Hübner $M$, Klek $S$, et al. ESPEN guideline: Clinical nutrition in surgery. Clin Nutr. 2017;36(3):623-50.

49. O'Brien S, Twomey M, Moloney F, Kavanagh RG, Carey BW, Power D, et al. Sarcopenia and postoperative morbidity and mortality in patients with gastric cancer. J Gastric Cancer. 2018;18(3):24252.

50. Li M, Kong $Y$, Chen $H$, Chu A, Song G, Cui $Y$. Accuracy and prognostic ability of the SARC-F questionnaire and Ishii's score in the screening of sarcopenia in geriatric inpatients. Braz J Med Biol Res. 2019;52(9):e8204.

51. Parra BFCS, de Matos LBN, Ferrer R, Toledo DO. SARCPRO: Proposta de protocolo para sarcopenia em pacientes internados. BRASPEN J. 2019;34(1):5863.

52. Ritch CR, Cookson MS, Clark PE, Chang SS, Fakhoury K, Ralls $V$, et al. Perioperative oral nutrition supplementation reduces prevalence of sarcopenia following radical cystectomy: Results of a prospective randomized controlled trial. J Urol. 2019;201(3):470-7. 
Received in: 11/03/2020

Accepted for publication: 14/05/2020

Conflict of interest: no.

Funding source: none.
Mailing address:

Diana Borges Dock-Nasimento

E-mail: dianadock@hotmail.com

(c) (i) 